\title{
Ultrastructure of Theileria-infected blood cells of loggerhead turtles
}

\author{
Alessandra Pica ${ }^{1}$ \\ Received: 19 June 2015 / Accepted: 22 June 2015 / Published online: 11 July 2015 \\ (C) Springer-Verlag London 2015
}

The authors are grateful to Drs. Stacy and Harvey et al. for their comments concerning Caretta caretta theileriosis. It gives us an opportunity to clarify and expand our statements as well as to offer further micrographic evidence relative to understanding this condition. This report regarding theileriosis is based on observations that were made over a period of about 12 years and includes an analysis of multiple hematological parameters derived from a large number of C. caretta obtained from inhabitants of the Mediterranean Sea (see Basile et al. 2012). In spring 2011, two specimens of $C$. caretta, completely covered by leeches, were brought to the Turtle Center of the Zoological Station of Naples. The leeches were recognized as Ozobranchus margoi, well known as turtle leeches (see figure in Di Santi et al. 2012).

The diagnostic process of theileriosis began with the detection of eosinophilic leukocytosis (Fig. 1a, Di Santi et al. 2012, and here in Fig. 1). It is well acknowledged that eosinophilia is a very frequent manifestation of parasitic infection in vertebrates. The first notable observation that was made was the presence of bacillary rodbayonet-shaped inclusions in erythrocytes ("the most useful guide to the genus Theileria," Kreir 1977) followed by their recognition in leukocytes. An abundant number of techniques were utilized to identify the

Alessandra Pica

alessandra.pica@unina.it

1 Department of Biology, University of Naples Federico II, Via Mezzocannone 8, 80134 Naples, Italy parasite. The first step was to conduct weekly hemograms on the two specimens which embraced morphologic analysis of blood films for parasitized cells Figs. 2-7, 8-9, 10-12, and 13). In addition, samples were preserved in EPON preparations to study them under TEM (see enclosed unpublished photographs of Figs. 14-15, 16-17, 18-19, 20-21, 22-25, and 26-27). During the stage of infection, osmotic fragility tests were conducted to establish whether the parasitic infection resulted in an alteration of erythrocytic osmotic fragility. When the stage of infection visually affected the leukocytes in the blood smears, buffy coat preparations of both subjects were prepared and cultured. The results of these tests confirmed the presence of an

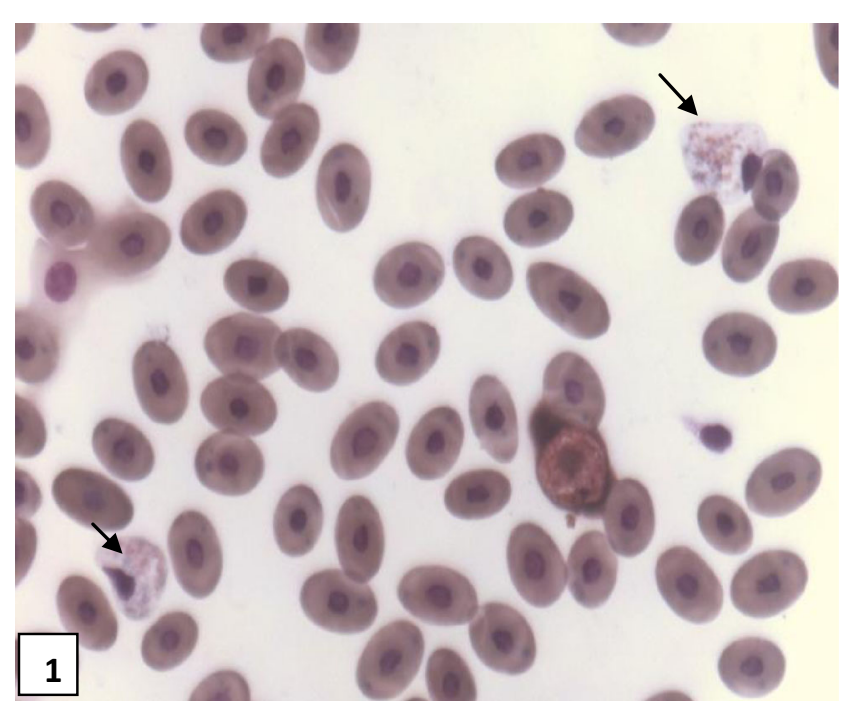

Fig. 11 Eosinophilia in blood smears of parasitized C. caretta: two eosinophilic granulocytes (arrows) in the same microscopic area. MGG stain (A. Pica) 

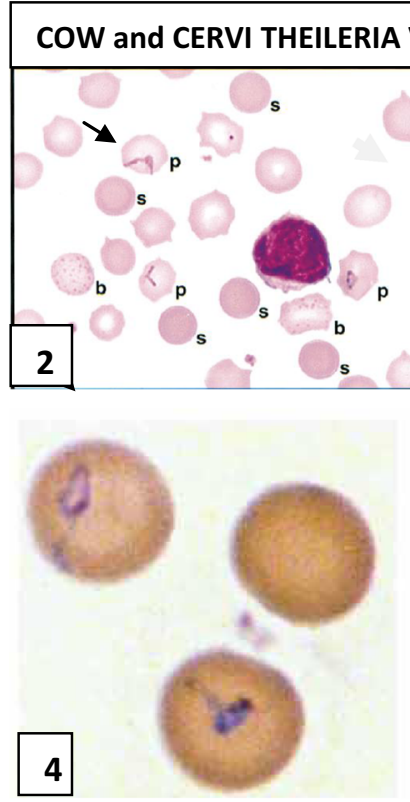

3
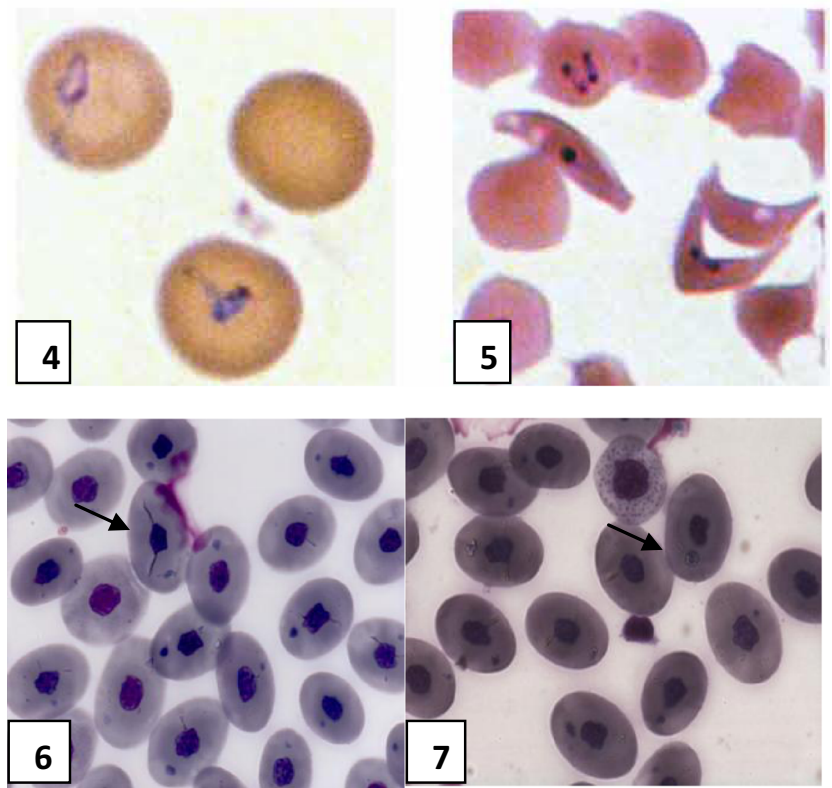

Figs. 2-7 2-3 Cow erythrocytes ( $p$ ) contain rod and racquet piroplasms (arrows) (Stockham et al. 2000). 4 Single Theileria buffeli-like organisms in two erythrocytes in blood from a pregnant Simmental cow. WrightGiemsa stain (see Harvey 2011, page 43). 5 Theileria cervi organisms in erythrocytes in blood from a white-tailed deer. Several drepanocytes (sickle erythrocytes) are present. Wright-Giemsa stain (see Harvey 2011, page 43. 6-7 Rod and racquet piroplasms (arrows) in Caretta erythrocytes. MGG stain (A. Pica)

\section{CATTLE THEILERIA Vs CARETTA THEILERIA:}

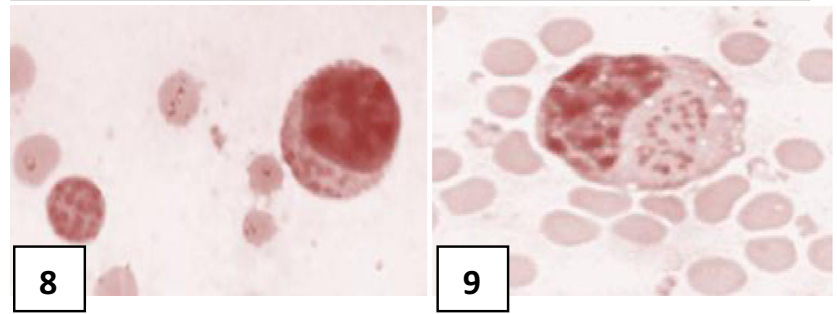

Figs. 8-9 8-9 Giemsa-stained blood smears of infected cattle: extra- and intracellular schizont forms of Theileria annulata parasites. Intraerythrocytic piroplasm forms are also evident $(\times 1000)$ (Hassan et al. 2012)

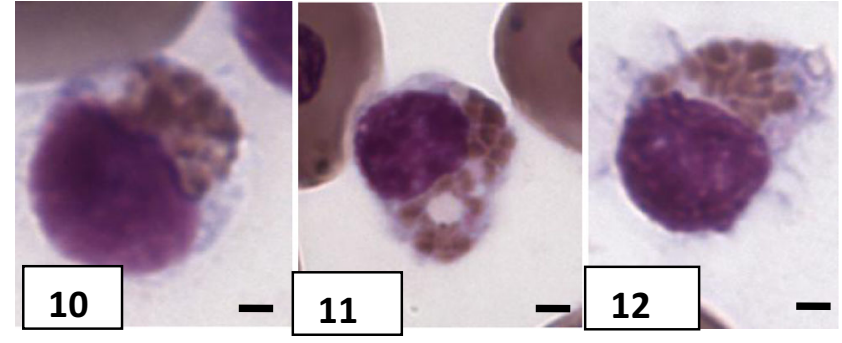

Figs. 10-12 10-12 Caretta lymphocytes infected by Theileria. MGG stain (A. Pica)

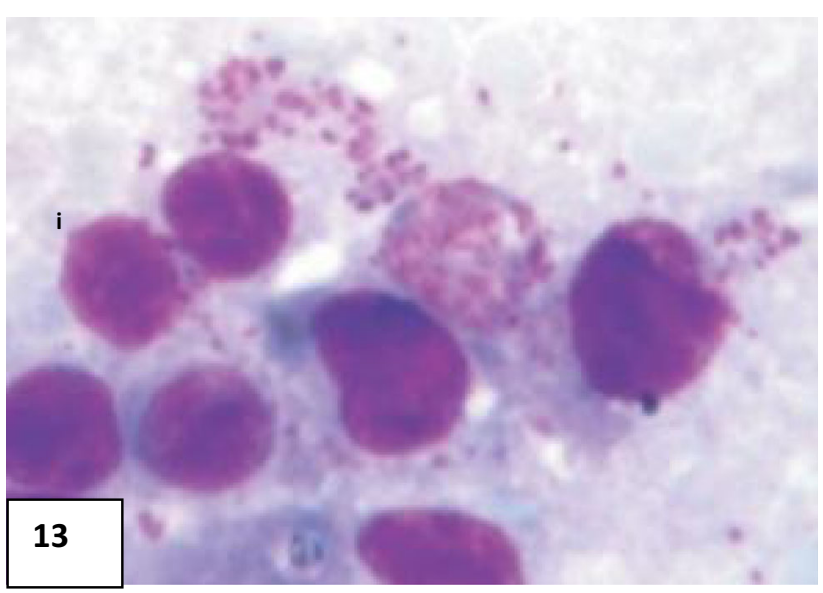

Fig. 1313 Theileria annulata schizonts in lymphoblastoid cells. Giemsa stain. $\times 1000$ (Mirzaei 2007, http://parasitol.kr/journal/ view.php?number=194)

\section{TEM OF THEILERIA PARASITIZED RBCS: CARETTA Vs COW}
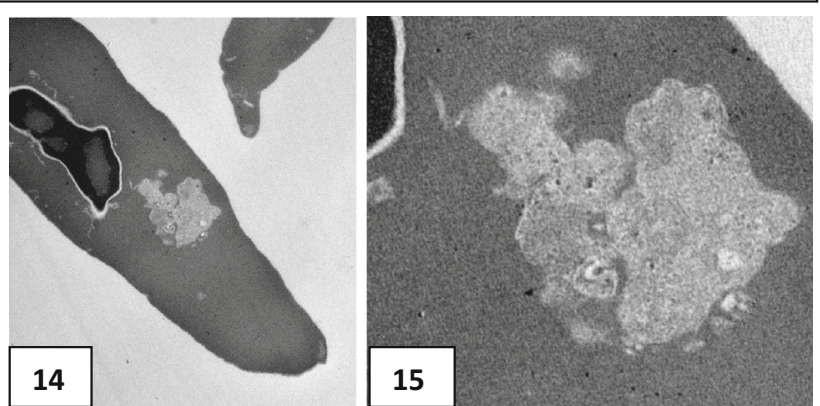

Figs. 14-15 First step: Theileria piroplasm in Caretta RBCs (A. Pica)

intense proliferation of transformed cells containing parasite particles over a period of several months (as reported, Di Santi et al. 2012). A molecular study of the parasite would have been executed as a final step, if the parasite were not recovered from the infected turtles. However, the cytologic evidence of the parasite 

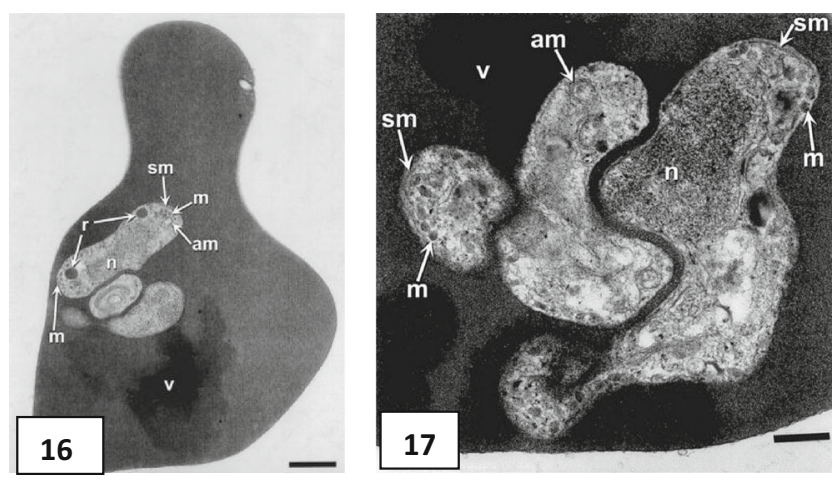

Figs. 16-17 Theileria piroplasm in an infected cow's RBCs (Stockham et al. 2000)

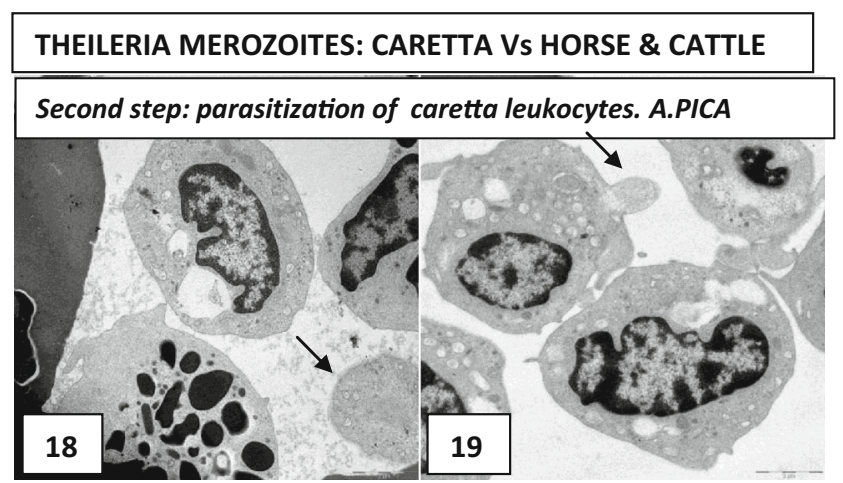

Figs. 18-19 18 An external merozoite and 19 a merozoite entering a Caretta leukocyte (arrows) (A. Pica)
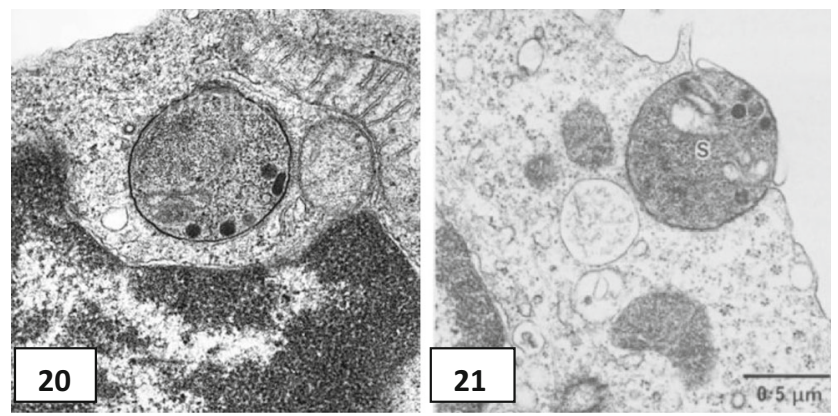

Figs. 20-21 20 Theileria parva infecting a lymphocyte (Don W. Fawcett (1987)/Science Photo Library). 21 A sporozoite $(S)$ entering a bovine lymphocyte (Shaw et al. 1991)

disappeared from the blood smears of both subjects after 4 months of veterinarian therapy as reported by $\mathrm{Di}$ Santi et al. (2012).

In summary, the aggregate of observations initiating with the leech infestation, including TEM observations, which were not included in the original discussion in

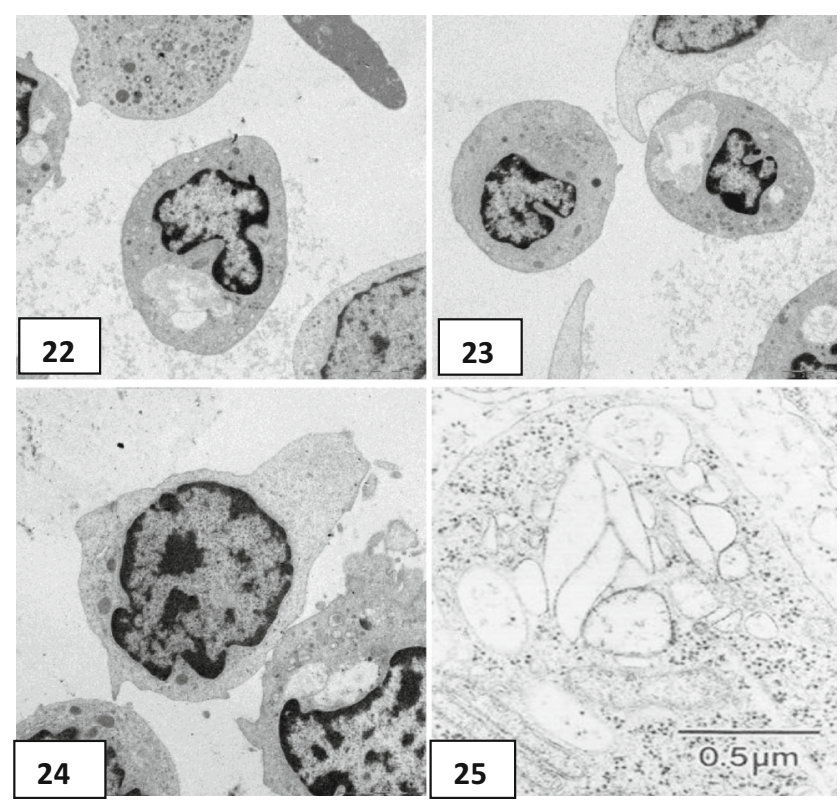

Figs. 22-25 22-24 Vacuolization of Theileria schizonts in Caretta leukocytes after therapy (Di Santi et al. 2012). 25 Treatment of schizont-infected bovine cells with brefeldin A leads to a rapid vacuolation (http://www.ilri.org/InfoServ/Webpub/fulldocs/ ILRADre1993v11n1/thesecre.htm)

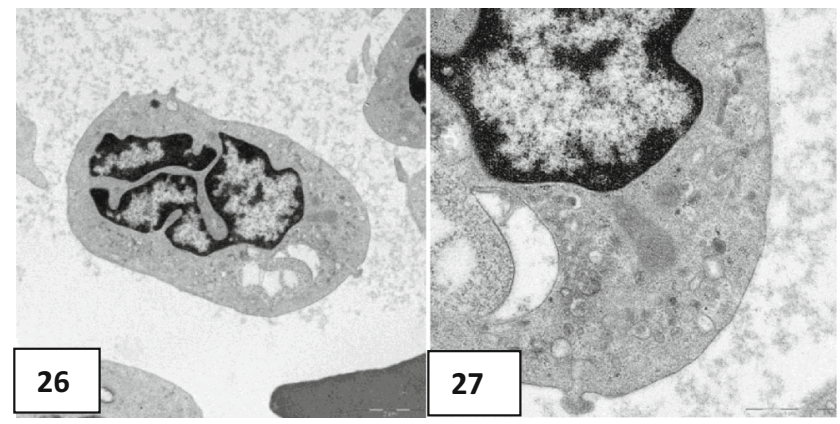

Figs. 26-27 A curved form of Theileria in a Caretta leukocyte (A. Pica)

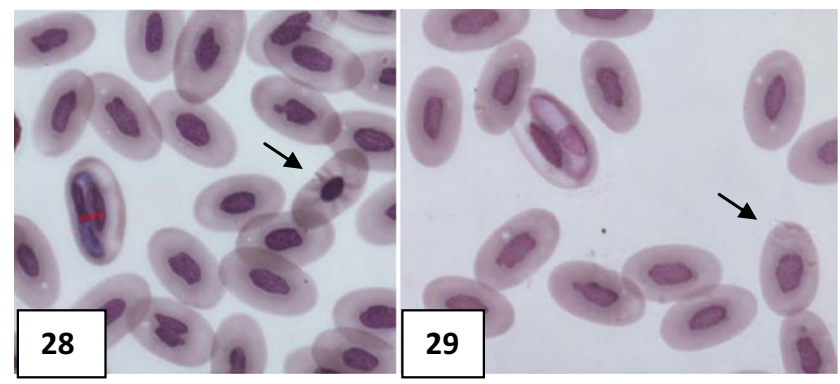

Figs. 28-29 Blood smears of a parasitized real python. Artifacts are indicated by arrows (A. Pica) 
order to keep the length of the report within practical limits (but enclosed here), demonstrate Theileria infestation of the two $C$. caretta. It also illustrates the positive response to medical therapy. Many workers have grappled with such a diagnosis using only morphologic observations (Collins et al. 1986; Stockham et al. 2000; Lainson 2007 as well as Harvey 2011).

Regarding the possibility that the observed inclusions were artifacts, it should be kept in mind that the recognition of the parasite was made on the basis of abundant cytologic findings (at LM and TEM), their cyclic nature, the clonal expansion of infected cells in culture, and their final disappearance from the affected turtles. The capacity of this parasite to cause host cell transformation is unique among eukaryotic pathogens. In fact, as textually reported by Marsolier et al. (2015), "Theileria is the only Genus that transforms its mammalian host cells." In addition, the detection of active erythrophagocytosis in circulating blood is another recognized phenomenon in response to parasitization (Jaensch and Raidal 2006; Ruggiero et al. 2014). Moreover, Theileria-infected cells were detected and photographed in ideal areas in the center of microscopic fields and not in thick-smeared regions. As an example, artifacts observed in red blood cells in smears of a python by our research group are attached below (Figs. 28 and 29).

\section{References}

Basile F, Di Santi A, Ferretti L, Bentivegna F, Pica A (2012) Hematology of the Mediterranean population of sea turtle (Caretta caretta): comparison of blood values in wild and captive, juvenile and adult animals. Comp Clin Pathol 21:1401-1406
Collins GH, Whittington RJ, Canfield PJ (1986) Theileria ornithorhynchi Mackerras, 1959 in the platypus, Ornithorhynchus anatinus (Shaw). J Wildl Dis 22(1):19-24

Di Santi A, Basile F, Ferretti L, Bentivegna F (2012) A Pica Hemoparasitization by Theileria in the loggerheads Caretta caretta of the Mediterranean Sea. Comp Clin Pathol 21(1):63-71.

Fawcett DW, Grootenhuis JG, Morzaria SP, Conrad PA (1987) Ultrastructure of the intraerythrocytic stage of theileria species from cattle and waterbuck. Tissue Cell 19:643-655, http:/hdl.handle.net/10568/29670

Harvey JW (2011) Veterinary hematology: a diagnostic guide and color atlas

Hassan AH, Salmo NA, Ahmed JS (2012) Pathological and molecular diagnostic study of theileriosis in cattle in Sulaimaniyah province, Iraq Proceeding of the Eleventh Veterinary Scientific Conference, 306-314

Kreir J (1977) Parasitic protozoa, volume IV: Babesia, Theileria, Myxosporida, Microsporida, Bartonellaceae, Anaplasmataceae, Ehrlichia, and Pneumocystis. Academic Press, Inc. (London), LTD, Page 89

Jaensch SM, Raidal SR (2006) Peripheral erythrophagocytosis in two reptiles. Comp Clin Pathol 15:113-116

Lainson R (2007) Theileria electrophorin sp., a parasite of the electric eel Electrophorus electricus (Osteichthyes: Cypriniformes: Gymnotidae) from Amazonian Brazil. Mem Inst Oswaldo Cruz 102(2):155-157

Marsolier J, Perichon M, DeBarry JD, Villoutreix BO, Chluba J, Lopez T, Garrido C, Zhou XZ, Lu KP, Fritsch L, Ait-Si-Ali S, Mhadhbi M, Medjkane S, Weitzman JB (2015) Theileria parasites secrete a prolyl isomerase to maintain host leukocyte transformation. Nature 520: 378-397

Mirzaei M (2007) Treatment of natural tropical theileriosis with the extract of the plant Peganum harmala. Korean J Parasitol 45(4):267271

Ruggiero MG, Ferretti L, Glomski C, Pica A (2014) Erythrophagocytosis in circulating blood of loggerhead turtles Caretta caretta: the pitting of Heinz bodies. J Exp Zool 9999A:1-7

Shaw MK, Tilney LG, Musoke AJ (1991) The entry of Theileria parva sporozoites into bovine lymphocytes: evidence for MHC class I involvement. J Cell Biol 113(1):87-101

Stockham SL, Kjemtrup AM, Conrad PA, Schmidt DA, Scott MA, Robinson TW, Tyler JW, Johnson GC, Carson CA, Cuddihee P (2000) Theileriosis in a Missouri beef herd caused by Theileria buffeli: case report, herd investigation, ultrastructure, phylogenetic analysis, and experimental transmission. Vet Pathol 37(1):11-21 